\title{
Enhancing Innovation Competences through a Research-based Simulation: From Framework to Hands-on Experience
}

\author{
Begoña Montero Fleta \\ Universidad Politécnica de Valencia
}

Received: 8 June 2012 / Accepted: 28 January 2013

ISSN: $1697-7467$

\begin{abstract}
The present study, based on the principles of simulation methodology, sets forth the implementation of experiential learning to enhance transferable skills and the development of innovation competences in an English course setting. The innovative contribution of the educational research undertaken is an experiential learning tool, devised within the tenets of the simulation methodology: an open simulation approached from competence framework to a hands-on experience. The Scenario, Profiles, Facilitator's Directions and Debriefing Process of the simulation are described in detail throughout the paper as well as the educational implications.

Keywords: simulation, experiential learning, innovation competences, communication skills in English.

Mejora de las competencias de innovación por medio de una simulación basada en investigación: desde el marco teórico a la implementación del aprendizaje experiencial

RESUMEN. El presente estudio, basado en los principios de la metodología de la simulación, describe la implementación del aprendizaje experiencial para potenciar las destrezas interpersonales y el desarrollo de competencias de innovación en el entorno de un curso de inglés. La contribución innovadora de la presente investigación educativa es una herramienta de aprendizaje experiencial, creada a partir de los principios de la metodología de la simulación: una simulación abierta abordada desde el marco de las competencias a la experiencia. El trabajo presenta el Escenario, los Perfiles, Directrices del Facilitador y el Proceso de puesta en común y evaluación, así como las implicaciones didácticas.

Palabras clave: simulación, aprendizaje experiencial, destrezas de innovación, destrezas comunicativas en lengua inglesa.
\end{abstract}

\section{INTRODUCTION}

Lifelong learning has been defined as "all purposeful learning activity, undertaken on an ongoing basis with the aim of improving knowledge, skills and competence" (Commission of the European Communities, 2000: 7). Learning takes place throughout life from our daily interactions with others and with the world around us. The demands of the current 
international market have required a change in the learning needs and styles so as to be able to form professionals with different modes of knowledge: academic scientific knowledge and the knowledge originated in situations in which there is a need to solve practical and application problems (Gibbons, in Kairisto-Mertanen et al., 2011). Hence, in educational contexts the accumulation of knowledge content is losing meaning and the acquisition of attitudes is gaining presence (Pérez-Peñalver et al., 2012). University programmes have now the responsibility of creating a learning environment for enabling lifelong learning in a continuous, permanent pursuit and the development of multidisciplinary professional skills. To comply with this challenge and reach the new professional competence demands, new frameworks for learning are required (Lehto et al., 2011). University degrees need to increase their emphasis on the development of core skills related to generic skills, i.e., "those transferable skills which are essential for employability at some level" (Kearns 2001: 2); these skills also referred to as professional skills, soft skills, key competences, key skills or personal skills. They are applicable to a wide range of tasks and contexts beyond the university setting, and all graduates should possess them (Gilbert et al., 2004); the intensity with which they might be required may depend on the job itself.

The European Parliament Council in the "Recommendations on the Establishment of the European Qualifications Framework for lifelong learning" (2008), defines competence as "the proven ability to use knowledge, skills and personal, social and/or methodological abilities, in work or study situations and in professional and personal development". These competences will help students to gain employment and to progress in their workplace. Generic skills are the subject of considerable debate in universities in recent times. Identifying and assessing the competence of these skills is today an issue for education policy makers, e.g.: The European Union project INCODE (Innovation Competences Development Project 518132- LLP-1-2011-1-FI-ERASMUS-FEXI) aims at designing and validating a measuring tool of innovation competences under which many generic skills can be identified, i.e., research skills, communication, sharing information, teamwork, hands-on experience, interaction skills, problem-solving skills, creativity, among others.

According to Shuman et al. (2005), professional skills can certainly be mastered as part of a modern engineering education format that utilizes active and cooperative learning and teaches engineering in its appropriate context; and not necessarily taught in the traditional lecture format. The present research provides a framework for implementing an approach where generic skills acquisition is involved in an experiential learning process. The project has been devised in a university English course to foster students' awareness of the skills required in a professional setting. A First Phase of the project, presented in a previous research by the author (Montero-Fleta, 2012), undertook an empirical approach to research job advertisements and to analyze the employability skills required. The generic skills then identified are now experienced in a hands-on framework to foster their acquisition innovatively, as well as to improve communication skills in English. The hands-on approach used in this Second Phase of the project has been devised as a simulation that helps participants put into practice the generic professional skills needed as a path to employment. The Scenario, Profiles, Facilitator's Directions and Debriefing Process devised are described in detail throughout the paper. 


\section{Theoretical BACKGround. EXPERIENTIAL LEARNING AND SIMUlation}

Active learning refers to a mode of instruction that focuses the responsibility of learning on the learners; students become actively engaged in the learning process through carefully planned experience. One of the strengths of active learning is related to learning effectiveness. Dale (1969) reflects in his "Cone of Learning" that the activities performed in the learning process, the senses used and the nature of the involvement have a clear influence on learning. According to this author, by means of verbal and visual reception (i.e., passive involvement), after two weeks we remember $10 \%$ of what we read, $20 \%$ of what we hear, $30 \%$ of what we see and $50 \%$ of what we see and hear. However, after two weeks with active involvement in which reception, participation and performance are implied, we still are able to remember $70 \%$ of what we say (e.g., participating in a discussion or giving a talk) and $90 \%$ of what we say and do (e.g., doing a dramatic presentation, simulating the real experience or doing the real thing, which is the essence of the present approach). In the same line, Ausubel (2002) contends that a major learning retention is the product of an active process. Hence, the more actively involved we are, the better we will remember what we have been taught.

From a theoretical perspective, this project is in line with active learning and the experiential learning process proposed by Kolb (1984), inspired by the work of Piaget, Lewin or Dewey. The experiential learning process theory (ELT) highlights some skills that stand out above others as a result of own life experiences and current environmental demands. Kolb defines learning as "the process whereby knowledge is created through the transformation of experience" (Kolb, 1984: 41). The four-stage experiential learning process, postulated by Kolb, engages the learners in the situations that arise. It is necessary to reflect on the experiences, generate concepts and integrate observations into logically solid theories. The learner must finally be able to use these theories to make decisions and solve problems. The umbrella of experiential, has many advantages related to achieving personal growth, as well as enhancing and reinforcing academic learning by bridging the theory and practice. Learning occurs when overcoming obstacles in order to accomplish a meaningful goal. From the experiential learning theory, Kolb and Kolb (2009) devised a way that approaches life experiences with a learning attitude: the "Learning way". For these authors experience can be transformed by:

1. Developing the capacity for experiencing. Personal engagement in concrete situations helps to develop interpersonal relationship skills of leadership and relationships that may help in the development of the experiencing mode of learning.

2. Developing the capacity for reflecting. Information gathering and information analysis can aid in the development of the reflecting mode of learning which in turn can lead to the assimilation of new thoughts and ideas.

3. Developing the capacity for thinking. Engagement in thinking can be enhanced with the creation of scenarios for action. Analytical skills of theory building, quantitative data analysis, and technology management can aid in the development of the thinking mode of learning. 
4. Developing the capacity for action. Action skills of initiative, goal setting, and action taking can aid in the development and expression of the acting mode of learning. (Kolb and Kolb, 2009).

Schon (1983) defines professionals as people who make the link between knowing and doing through reflective practice: they think in action. To implement this tenet in an educational context which forms future professionals, the pedagogical approach chosen in this study is simulation, a current, innovative, motivating methodology, centered on the learner and oriented to the process and to the product. Simulation is widely acknowledged as a powerful teaching technique, which firmly rests on the basic principles of experimental learning. The stages and the developing capacities involved in experiential learning have a clear parallelism with the phases of a simulation. Figure 1 shows how the simulation methodology is in line with the theoretical models established in experiential learning:

Figure 1. Parallelism between the stages of experiential learning and simulation

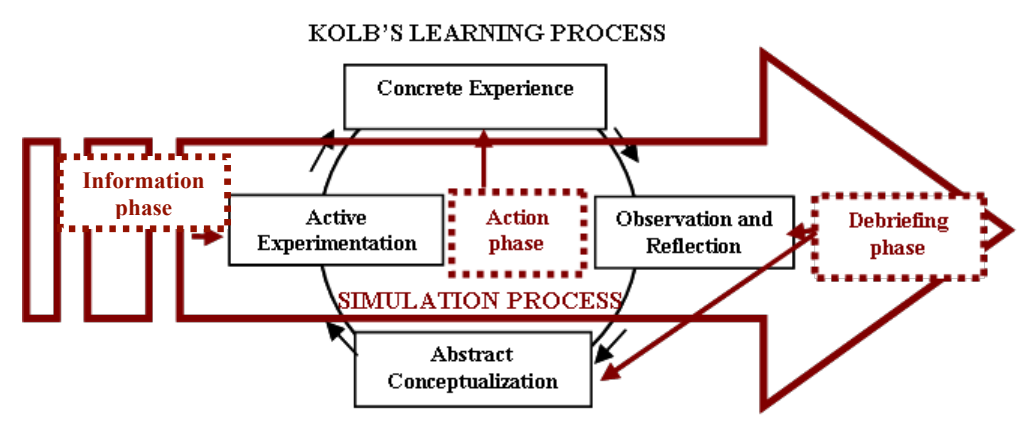

The concrete experience corresponds to the action phase of the simulation, when participants implement their roles based on the scenario. The observation and reflection stage, together with the abstract conceptualization stage, take place in the debriefing phase of the simulation when participants in the simulation observe and reflect on the process and product, and attempt to conceptualize a theory from their observations. Kolb's active experimentation is linked to the information phase of the simulation, that is, when participants get all the information needed to begin the action, including their own concepts for the new experience. Finally, in the debriefing stage, experiences are related with concepts and transferred to "real world" concrete experiences. Although debriefing traditionally takes place at the end of the simulation process, it is the core of the learning process (Lederman, 1992; Steinwachs, 1992; Thiagarajan, 1992; Petronek, 2000; Crookall, 2010 or Kriz, 2010). García-Carbonell and Watts (2010), and Peters et al. (2004) even propose continuous debriefing sessions to discuss the processes and finding solutions to issues encountered.

Dumblekar (2004) highlights the characteristics of simulations which make them suitable for the purpose of the current research: simulations are replica of reality which promote learning through interactive experiences; they promote creativity amongst the participants; they are experiential and rigorous; they are aimed at developing soft skills; they can be used 
to learn about a particular subject matter and to learn how to learn from experience. For Greenblat (1988:16) the strengths of simulation include "increasing motivation and interest, conveying information or reinforcing information already given in another format, skill development, attitude change and self/collective-evaluation". García-Carbonell and Watts (2010), and García-Carbonell and Watts (2012) add meeting academic objectives, career objectives and personal growth objectives as important added values of simulation.

One aspect which is noteworthy in a simulation approach is the teacher's role, which definitely implies a dramatic change towards the traditional one. The teacher ceases to be a traditional teacher and becomes a facilitator. His/her role is to guide and assist students in their learning and his/her performance is crucial in the information phase or briefing, when presenting the approach. Little interference or directions will be provided in the performance of participants, i.e., the action phase. Again the facilitator becomes essential in conducting the debriefing session to get the most from the students. The emphasis, thus, turns away from the instructor and the content, towards the learner (Gamoran et al., 1998). On balance, the facilitator creates the environment, provides guidelines and expects the learners to arrive at their own conclusions. Finally, the facilitator assesses performance by measuring the achievement of the learners, the quality of the learning experience and courseware.

By means of an experiential learning approach based on a simulation, students may gain real world experience in higher education. In order to be successful in meeting objectives, experiential learning purposes have to reflect the learner's needs, and settings have to be considered realistic by the learner. In this context, the justification for the present research is that practical teaching strategies and new learning opportunities must be provided so that learners may be ready for new experiences and internalize information into their existing knowledge through experience. The present study sets forth the simulation "Seeking the project engineer", framed in a real life scenario: a job recruiting process setting. As GarcíaCarbonell and Watts (2010) point out, letting students get immersed in a real life situation in which they are encouraged to perform a real situation model with other colleagues facilitates learning to occur.

The hypothesis set for the present study is that a simulation may make participants aware of the necessary skills so as to be able to attain successful employment outcomes, and that a simulation may facilitate the development of new competences of high demand in the labour market (see Andreu-Andrés et al., 2009).

\section{Aim And SCOPE OF THE STUdy}

The underlying aim for this approach is to establish a realistic learning environment that will foster the acquisition of professional skills. The objectives pursued are to create the network that students will need in their working lives and to improve communication skills in English. Apart from specific technical skills required for the job, recruitment and selection processes demand the candidates' generic skills and attributes needed for the job. The selection process delves into the attitudes and skills of the applicants and their competence in facing situations innovatively by showing creativity and initiative. Thus, to meet these demands, a hands-on approach to professional skills has been devised, integrated into the curriculum of an English course. The present research is based on a recent project carried 
out with students of English in a university engineering degree over the course of the academic year 2011/2012. The level of English of the students was intermediate. The objective of the course was, on the one hand, to develop fluency, accuracy, quality and correctness in spoken and written language. On the other hand, objectives looked beyond these linguistic outcomes in the English language syllabus, and pursued the acquisition of professional skills oriented towards the development of students' innovation competences.

\section{The Design PRoCess OF THE SIMUlation: "SEEKING THE PROJECT EN- GINEER"}

The design process of "Seeking the project engineer" followed all the five stages postulated by Greenblat (1981) as the essence of simulations: the first stage is to set objectives and parameters; the second is to develop the model; the third is to decide about the representation; the fourth is the construction and modification of the simulation; and the final stage is to prepare the simulation to be used by others. "Seeking the project engineer" is implemented in a two-phase research project. The First Phase was dealt with in detail in Montero-Fleta (2012). Let us summarize it so as to better understand the Second Phase:

\subsection{First Phase}

The First Phase of the project developed in the course 2010-2011 required the students to work in groups to research professional skills through job advertisements from their field of studies (see Montero-Fleta, 2012 for a description of the process and research undertaken). The online positions found were analyzed from the point of view of the employability skills required by the international job market. Groups met weekly to exchange opinions and used wikis to complete the required tasks collaboratively.

Groups: Three to five students per group.

Tasks: 1. To research the generic skills required in online vacancies in the students' field of studies.

2. To hand in a written report of the results of the research undertaken.

3. To deliver an oral group presentation on the results obtained.

Time alloted: The activity was assigned at the beginning of the course. Students were given 6 weeks to prepare the task assigned.

The following table reveals the results obtained from the different students' group analyses of engineering online vacancies. The most frequent generic skills encountered are arranged in descending order in Table 1: 
Table 1. Generic skills most often demanded in job positions.

\begin{tabular}{|l|}
\hline SKILLS IN JOB VACANCIES \\
\hline 1. Communication skills \\
2. Teamwork \\
3. Leadership \\
4. Innovation skills \\
5. Problem-solving skills \\
\hline
\end{tabular}

The First Phase of the research project was followed by a debriefing session in which the facilitator sought information on group performance and students' feedback on the research undertaken. This session revealed the points of views of the participants on their initial perceptions on the skills of higher demand in the labour market, their findings and the practice of these skills in different subjects taught at university. Most relevant was the participants' feedback on their engagement and the development of skills during the performance, as suggested by Andreu-Andrés and García Casas (2011). In our teaching context, group members shared responsibilities in the selection of job vacancies and analyses. They felt motivated and willing to participate in the learning activity, as claimed by Marín-García et al. (2009) and Gardner (1985). What is striking and motivating is that, in the debriefing session, students agreed on the real implication of the majority of the skills found in the vacancies, in the research undertaken: communication skills, teamwork, innovation skills, problem-solving skills and critical thinking had been put into practice when reading, reflecting, discussing, agreeing, writing, producing and revising.

\subsection{Second Phase}

An activity which has shown itself to rank high as a "motivator" in the classroom is precisely simulation (Garris et al., 2002, Choi and Johnson, 2005). Thus, for the Second Phase of the project, a hands-on activity was designed on the framework of the research on generic skills previously made by the students. i.e., "Seeking the project engineer ", a simulation, of a professional work recruitment process, to put into practice the skills needed.

\subsubsection{Scenario: Briefing Sheet}

SEARCH, a Human Resource (HHRR) enterprise is recruiting candidates for a position of a Project Engineer sought by Kendal Manufacturing, Inc. The company needs two engineers provided with specific innovation competences. Table 2 shows the online job offer published by Kendal Manufacturing: 
Table 2. Online job vacancy.

\section{PROJECT ENGINEER VACANCY}

Kendal Manufacturing, Inc ${ }^{l}$, a leading manufacturer is seeking two full time Project Engineers

\section{POSITION RESPONSIBILITIES}

- Perform project management duties related to the launch of new products and engineering changes to existing products;

- Provide customer support via product design advice and problem solving assistance;

- Prepare quotations for new products \& engineering changes to existing products;

- Determine sourcing for new tools;

- Create and maintain engineering documents;

- Monitor performance to tooling budget;

- Provide technical support to manufacturing.

REQUIRED

- Ability to communicate in English orally and in writing;

- Ability to interact collaboratively in teams;

- Ability to lead groups;

- Ability to think creatively and innovatively.

Out of the many applications received, SEARCH has selected three candidates whose CVs. best meet the requirements for the position offered. A SEARCH panel made up of two SEARCH managers, i.e., the HHRR and General Manager, has first assessed the three applicants against basic eligibility, general education requirements, and additional education requirements for two positions of project engineer. SEARCH has found similar qualifications in the three candidates. In a personal interview, the same panel of SEARCH Managers will assess the degree to which the candidates meet the skills and abilities required to perform the duties of the position offered. This interactive session with the candidates will be decisive in the recruiting process, as only two out of the three interviewed can be hired.

Two participants will play the role of SEARCH managers, while three participants will play the role of candidates for a job in the enterprise. Applicants have to show the skills and competences demanded. The hands-on activity in this Second Phase of the project consists in letting the managers find out the competences and skills of the candidates. In the recruiting process, the candidates have to show their competences.

Goals - To put generic skills into practice;

Profiles - HHRR and General SEARCH Manager;

- Three candidates competing for two project engineer vacancies;

${ }^{1}$ The real name of the enterprise has been concealed for the sake of anonymity. 
Time - Background study: 20 minutes for SEARCH managers, 10 minutes for candidates;

Action -20 minutes (time may vary).

\subsubsection{Profiles 1 and 2. HHRR and General SEARCH Managers}

As HHRR or General Manager you have already studied the three candidates' CVs. and have found similar backgrounds, qualifications, similar discipline-specific fundamental knowledge and experience in all of them. You are now seeking the candidates' competences and attitudes now demanded by the labour market. You know that you have to recruit and select staff effectively so as to make management processes work efficiently.

The skill and ability requirements for the project engineer positions are:

- Ability to communicate in English orally and in writing;

- Ability to interact collaboratively in teams;

- Ability to lead groups;

- Ability to think creatively and innovatively.

The interactive session with the three applicants selected has to be carefully designed. You will decide the strategy to be used. You have to prompt how the three candidates have to intervene and interact in the session. You have to devise a group dynamics with the three candidates based on a hypothetical situation characteristic of the post offered. Let the three candidates work together to find the best solution to the hypothetical situation posed. Analyse the innovation and creativity shown.

\subsubsection{Profiles 3, 4 and 5. PROJECT ENGINEER Candidates}

SEARCH, a HHRR enterprise is recruiting candidates for a position of two project engineers sought by Kendal Manufacturers, Inc. Out of the many applications received, you are one of the three candidates pre-selected on basic eligibility criteria, general education requirements, and additional education requirements for a position of PROJECT ENGINEER. In a second recruiting process phase, HHRR and General Managers will assess the degree to which you comply with the skills and abilities required to perform the duties of the position offered. This process will be held in a joint interactive session with the two SEARCH managers, you and the other two candidates. This session will be decisive in the recruiting process, as only two out of the three interviewed can be hired.

You are really interested in being one of the successful candidates. You have to show your competence on the following skills demanded by Kendal Manufacturers, Inc.:

- Ability to communicate in English orally and in writing,

- Ability to interact collaboratively in teams,

- Ability to lead groups,

- Ability to think creatively and innovatively 
Your interaction with the other candidates in the discussion on the hypothetical situation posed by the SEARCH Managers, must show your superiority and prove your competences, so as to be finally recruited! You have a maximum of 10 minutes to plan a creative and innovative interaction. Remember that SEARCH Managers will assess your competence of generic skills.

\subsubsection{Facilitator's Directions}

- Materials needed: Scenario: Briefing sheets;

- Profile sheets: ${ }^{\circ}$ HHRR and General Managers, Candidates;

- Time in Second Phase: ${ }^{\circ}$ Background study: 20 minutes for SEARCH managers, 10 minutes for candidates;

- Action: 20 minutes. (Time may vary).

- Background

- The activity is run with groups of 5 participants.

- A scenario is presented for participants. Individuals are assigned roles, and learners act out their roles within the activity:

- Two participants play the role of HHRR or general SEARCH managers [see individual profile sheets].

- Three participants play the role of candidates for two positions of project engineer sought by Kendal Manufacturers, Inc. [see individual profile sheets]

- Briefing

- Begin the exercise by dividing participants into groups of five for the First Phase of the simulation. Name the two SEARCH managers and three candidates for the two job vacancies.

- Allow managers 20 minutes to read over the scenario and profile sheets and to design the strategy and the hypothetical situation to offer the Candidates.

- Allow candidates 10 minutes to familiarize themselves with the skills/competences and plan how to solve the hypothetical situation.

- If multiple groups are run simultaneously, they should probably hold their sessions in separate rooms to avoid influencing other groups.

- Clarify any questions before beginning the action.

- Action SEARCH managers and candidates should interact for 20 minutes. Each candidate will use his/her own personal strategies to solve the situation creatively and convince the managers they are the best choice.

Note: The HHRR or general SEARCH managers must reach a justified decision on their choice of two out of the three candidates.

- Debriefing

When SEARCH managers have gathered valuable feedback from the candidates and decided who should get the job, a debriefing session will be started to explore feelings and learning from the experience regarding the final decision taken, the situation itself and the participants' performance. As debriefing is one of the most important phases of a simulation, significant learning is achieved when deep insight, including, not only process and product, but also feelings and reactions, is 
made explicit through reflection during this phase. The following questions may help in the debriefing phase:

Sample questions about competences and skills to be answered using a five-point Likert scale:

- Are you satisfied with your performance?

- Did SEARCH managers' questions and interaction helped to let you show your skills?

- As a candidate, were you able to show your teamwork skills?

- As a candidate, were you able to show your innovation skills?

- How effective do you think you were?

- Has this experiential learning activity made you aware of the need for generic skills in your future career?

Open questions about feelings and reactions:

- How do you feel about the task?

- How do you feel about the process?

- How do you feel about the time given?

- How have you been able to convince the SEARCH managers about your solution?

- What particular skills or strategies did SEARCH managers and candidates use to achieve their goals?

- Which candidate do you think performed better?

\subsubsection{Summary of the experiential learning activity}

- Organise groups with two SEARCH managers and three candidates each;

- Allow participants several minutes to read over their profile sheets;

- After participants have read their briefing sheets, clarify any questions posed;

- If SEARCH managers needed more time, give them example situations if they cannot come up with some in a few minutes;

- Allow each group about 20 minutes to discuss;

- Let SEARCH managers make their final decisions;

- Debrief with participants.

\section{EduCATIONAL IMPLicATIONS}

In the design of this project, emphasis on a balance of action, reflection, and application was required in order to provide successful learning experiences. The hands-on approach here described involved students in active participation; with future work perspectives. The simulation context challenged the students to identify and innovatively apply the best solution to a situation as well as to assess their performance and learn from it. The simulation fostered students' active engagement in learning by incorporating subject related knowledge and useful work related competences. The developing capacities posed by Kolb and Kolb (2009) in their "Learning way" were present throughout the approach: students got involved in a new experience which required preparation, reflective observation on their part; innovative ideas were applied by SEARCH managers in the design of a hypothetical 
situation; during the hands-on performance, the candidates showed their skills in solving the situation innovatively, so as to meet the demands of the current labour market. Finally, a follow-up debriefing phase, a phase of increasing interest in lifelong learning, reflected on what happened during the simulation, so as to extract maximum learning from the experience. Strengths and weaknesses were identified in this phase. Our personal experience has confirmed the hypothesis on the strengths of a experiential learning approach based on a simulation to develop current competence demands. Moreover, in our English language setting, the implementation of the simulation favoured exposure to language and the practice of communication skills in the medium of English. The simulation provided students with a challenging and rewarding experience that went beyond requirements outlined in the traditional curriculum framework.

\section{Conclusions and further Research}

Higher education has a relevant role to play in developing generic skills. The attainment of these skills encouraged the development of lifelong learning, an essential element of the European Higher Education Area. In the present approach, students faced a scenario that is representative of the types of situations they will encounter in the real world. The establishment of an engineering context provided an important basis for fostering students' motivation. The students' command of innovative generic skills was observed by the solutions generated to real life problems.

The introduction of new approaches in the classroom raises an important issue about teachers' academic support to innovate, particularly in traditional academic disciplines frequently centered towards traditionally set curricula. So as to prepare students for the new demands of the twenty-first century workplace, higher education institution must accommodate the teaching and learning methodologies and assessment strategies. A simulation, as the one here described, situates learning in a particular context that provides opportunities for authentic practice. This simulation encourages the development of a lifelong learning strategy to skills acquisition The simulation devised is also applicable in vocational training and secondary education, by making minor changes so as to tailor it to the learners' profile.

As research on assessment so far has mainly tested students' knowledge related to a particular discipline, ongoing research is further delving into assessment to develop tools to evaluate approaches to integrate transferable skills. To take the study forward, in a near future the feedback of employers can also be incorporated to the research.

\section{ACKnowledgments}

This paper has been written with financial support from the European Union within the Project 518132-LLP-1-2011-1-FI-ERASMUS-FEXI "INCODE - Innovation Competences Development" and the Universitat Politècnica de València, project PYME A13/11 2012 "Desarrollo de rúbricas y situaciones de evaluación para competencial transversales relacionadas con la innovación" (Development of rubrics and settings for the assessment of innovation generik skills) evaluated by the Comisión de Evaluación y Seguimiento de Proyectos de Innovación y Convergencia at the Universitat Politècnica de València and the AVAP (Agència Valenciana d'Avaluació i Prospectiva). 


\section{REFERENCES}

Andreu Andrés, M. A., García Casas, M. and Rising, B. (2009). “Assessment of Student Participation and Critical Thinking in Engineering Students' Teamwork", in WSEAS Transactions on Advances in Engineering Education, 12, 6: 464-477.

Andreu-Andrés, M. A. and García-Casas, M. (2011). "Perceptions of gaming as experiential learning by engineering students", in IJEE-International Journal of Engineering Education, Special Issue on Gaming, 27, 4: 795-804.

Ausubel; D. P. (2001). Adquisición y retención del conocimiento. Barcelona: Paidós.

Commission of the European Communities (2000): "A Memorandum on Lifelong Learning". Brussels, available from: http://www.bologna-berlin2003.de/pdf/MemorandumEng.pdf, accessed 25 April, 2013.

Choi, S. and Johnson, W. L. (2005). "Assessing Dynamic Aspects of Learner Motivation in Simulation/Gaming Based Foreign Language Learning Environment", available from: http://www.informatics.sussex.ac.uk/users/gr20/aied05/finalVersion/SChoi.pdf, accessed 25 April, 2013.

Crookall, D. (2010). "Serious Games, Debriefing, and Simulation/Gaming as a Discipline". Simulation \& Gaming, 41, 898-920.

Dumblekar, V. (2004). "Management simulations: Tests of effectiveness". Simulation \& Gaming: An Interdisciplinary Journal of Theory, Practice and Research, available from: http:/www. unice.fr/sg/resources/articles/dumblekar_2004_management.htm, accessed 20 May, 2012.

Dale, E. (1969). Audio-visual methods in teaching. New York: Dryden Press.

European Parliament Council (2008). "Recommendation of the European Parliament and of the Council of 23 April 2008 on the establishment of the European Qualifications Framework for lifelong learning". Official Journal C 111: 1-7, available from: http://eurlex.europa.eu/LexUriServ/ LexUriServ.do?uri=OJ:C:2008:111:0001:0007:EN:PDF,_accessed 20 May, 2012.

Gamoran, A., Secada, W. G. and Marrett, C. A. (1998). "The organizational context of teaching and learning: changing theoretical perspectives", in M.T. Hallinan, (ed.), Handbook of Sociology of Education. San Francisco, CA: Jossey Bass, 37-63.

García-Carbonell, A. and Watts, F. (2012). "Investigación empírica del aprendizaje de lenguas con simulación telemática", in Revista Iberoamericana de Educación, RIE. Estudios e Investigaciones: Didáctica de la Lengua y la Literatura, 59, 3, available from: http://www.rieoei.org/ deloslectores/4395Gcia.pdf.

García-Carbonell, A. and Watts, F. (2010). "The Effectiveness of Telematic Simulation in Languages for Specific Purposes", in Bungarten, T. (ed.), Linguistic and Didactic Aspects of Language in Business Communication. Hamburg: Universität Hamburg, 1-16.

Gardner, R. C. (1985). Social Psychology and Language Learning: the Role of Attitudes and Motivation. London: Edward Arnold.

Gilbert, R., Balatti, J., Turner, P. and Whitehouse, H. (2004). "The generic skills debate in research higher degrees", in Higher Education Research \& Development, 23, 3: 375-388.

Garris, R., Ahlers, R. and Driskell, J. E. (2002). "Games, Motivation and Learning: A Research and Practice Model”, in Simulation \& Gaming: An Interdisciplinary Journal, 33, 4: 441-467.

Greenblat, C. S. (1988). Designing Games and Simulations. An Illustrated Handbook. Newbury Park: Sage Publications.

Kairisto-Mertanen, L., Penttilä, T. and Nuotio, J. (2011). "Innovation for Competence Management", in Conference Proceedings. Lahti University of Applied Sciences. Series of C Articles, reports and other publications, 83: 25-33. 
Kearns, P. (2001). Generic Skills for The New Economy - review of research. Adelaide: NCVER.

Kolb, D. A. (1984). "Experiential learning: experience as the source of learning and development". Englewood Cliffs, NJ: Prentice Hall.

Kolb, A. and Kolb, D. (2009). "The Learning Way: Meta-cognitive Aspects of Experiential Learning", in Simulation \& Gaming, 40: 297-327.

Kriz, W. (2010). "A Systemic-Constructivist Approach to the Facilitation and Debriefing of Simulations and Games", in Simulation \& Gaming, 41, 5: 663-680.

Lederman, L. C. (1992). "Debriefing: Toward a Systematic Assessment of Theory and Practice", in Simulation \& Gaming, 23: 145-159.

Lehto, A., Kairisto-Mertanen, L. and Penttilä, L. (eds.) (2011). Towards Innovation Pedagogy. A new approach to teaching and learning for universities of applied sciences. Reports from Turku. University of Applied Sciences 100, Tampere: Tampereen Yliopistopaino-Juvenes Print Oy.

Marín-García, J. A., Martínez Gómez, M. and Lloret, J. (2009). "Enhancing Motivation and Satisfaction of Students: Analysis of Quantitative Data in Three Subjects of Industrial Engineering", in WSEAS Transactions on Advances in Engineering Education, 6, 1: 11-21.

Montero-Fleta, B. (2012). "Looking beyond linguistic outcomes: active learning and professional competencies in higher education", in Procedia, Social and Behavioral Sciences, 46: 1812-1819.

Pérez-Peñalver, M. J, Aznar-Mas, L. and Watts, F. (2012). "To adapt or to die when leaving the university: To promote innovation competence may be the key", in $6^{\text {th }}$ International Technology, Education and Development Conference. INTED: 2731-2736.

Peters, V., and Vissers, G. (2004). "A simple classification model for debriefing simulation games", in Simulation \& Gaming, 35, 1: 70-84.

Petranek, C. F. (2000). "Written debriefing: The next vital step in learning with simulations", in Simulation \& Gaming, 31, 1: 108-118.

Schon, D. A., (1983). The reflective practitioner: Toward a new design for teaching and learning in the professions. San Francisco: Jossey-Bass.

Shuman, L. J., Besterfield-Sacre, M. and McCourty, J. (2005). ABET "Professional skills - can they be taught? Can they be assessed?", in The Journal of Engineering Education, 94: 41-55.

Steinwachs, B. (1992). "How to Facilitate a Debriefing", in Simulation \& Gaming, 23: 186195.

Thiagarajan, S (1992). "Using Games for Debriefing", in Simulation \& Gaming, 23: 161-173. 